provided for three commercially available compositions. From topographical comparisons using scanning electron microscopy of both fritless and glass-containing gold films, Zeien agreed with previous workers that the former should display superior thermal and electrical properties and that wire-bonding characteristics using standard techniques should be improved. The validity of these conclusions was evaluated in a comprehensive test programme. Built in to this programme, which also included a study of wobble bonding of beam-lead frameworks, were assessments of the effects on strengths of bonds produced by small departures from recommended firing schedules of the gold films and in different post-firing treatments of bonded samples. Zeien showed, for example, that joint strengths of gold wires bonded either by thermocompression or by ultrasonics were not strongly dependent on the firing conditions tested, or influenced by post-bonding, long-term environmental exposures (e.g. $125^{\circ} \mathrm{C}$ for 500 hours). As expected, this was not found to hold true for aluminium wires ultrasonically bonded to gold, where the formation of brittle AuAl intermetallics readily accounts for the observed 25 per cent degradation in bond strength. On the other hand, wobble bonding of beam leads was found to be insensitive to the firing schedules of the gold films, and the joints showed no decrease in strength on prolonged exposure to elevated temperatures.

Compatibilities of glass-free gold metallisations with existing thick-film resistor and dielectric materials were also evaluated in this work. Thickfilm resistors terminated with pre-fired gold conductors displayed spreads in as-fired values of \pm 10 per cent with stabilities of around 0.1 per cent under dry lifetest conditions $\left(125^{\circ} \mathrm{C}\right.$ for 1,000 hours). Glass-free gold compositions were capable of being processed with crossover materials with no attendant loss in either adhesion or resolution, and the fired films showed no electrical continuity between the upper and lower electrode when spaced with this dielectric.

The improved properties of these novel materials should not only produce new areas of application for gold pastes, but also assist in removing one of the major causes of restricted life-times for thick-film circuits by increasing the yield of near-perfect bonds to metallised films on ceramic substrates. The anticipated increase in reliability of thick-film hybrid circuits will place this technology in a more favourable competitive position, capable of producing economically a wide range of microelectronic assemblies of advanced specification.

T. H. L.

\section{References}

1 R. G. Finch, "Gold in Thick-Film Hybrid Microelectronics", Gold Bull., 1972, 5, (2), 96

2 R. G. Loasby, N. Davey and H. Barlow, "Enhanced Property Thick-Film Conductor Pastes", Solid State Tech,. 1972, 15, (5), 46

3 B. R. Smith and R. L. Dietz, "An Innovation in Gold Paste", Proc. ISHM Symp., 1972, p. 2-A-5-1

4 S. K. Misra and A. C. D. Chaklader, F. Am. Ceram. Soc., $1963,46,(10), 509$

5 T. T. Hitch, "Adhesion, Phase Morphology and Bondability of Reactively-Bonded and Frit Bonded Gold and Silver Thick-Film Conductors", f. Elect. Mat., 1974, 3, (2), 553

6 B. R. Smith, U.S. Patents 3,799,890 and 3,799,891 and others pending

7 R. H. Zeien, "Characterisation of Thick Film Fritless Metallisation", Proc. ISHM Symp., 1974, p. 7

\title{
Thickness Measurement of Gold Deposits
}

Accurate and reliable determinations of the thickness of electrodeposited gold coatings are essential to both the electroplater and the user. The methods involved vary from spot checks by relatively simple techniques to sophisticated procedures to form the basis of statistical control of production. A great number of testing methods is now available, some direct-giving the true linear thickness of the deposit-and some indirect, measuring thickness in terms of weight of coating per unit area or through the response of the deposit to some form of external radiation.

A useful review of all the available techniques suitable for gold electrodeposits, with their individual advantages and limitations, has now been prepared by F. H. Reid and published in the first and second issues of Circuit World, the journal of the recently formed Association of Circuit Technologists.

The direct optical methods described include the simple procedure of determining thickness on a carefully prepared section of the coating under the microscope, the chord method in which thickness is derived from microscopic measurement on an oblique section exposed by grinding a shallow groove on the coating surface, the use of interference microscopy to measure the difference in level between unplated and plated areas, the depth of focus method, and the light profile method of measuring step height between plated and unplated areas.

The chemical and electrochemical methods reviewed include the simple strip and weigh procedure, and anodic dissolution at constant current in a test cell, the time for dissolution giving a measure of thickness.

The activation techniques, more suited to large numbers of routine measurements, include $\mathrm{X}$-ray and beta-ray back scatter. While the former involves a high capital cost of equipment, the latter technique is now supported by the availability of relatively inexpensive and compact instrumentation and provides the most generally convenient non-destructive method.

The author emphasises, among other factors, the importance of both electroplater and user employing the same method of measurement, or, if this is not practicable, of tests being carried out to establish the closest correlation between the methods adopted. 